\title{
Initiation of Failure for Masonry Subject to In-Plane Loads through Micromechanics
}

\author{
V. P. Berardi \\ Department of Civil Engineering, University of Salerno, Via Ponte don Melillo, 84084 Fisciano, Italy \\ Correspondence should be addressed to V. P. Berardi; berardi@unisa.it
}

Received 17 December 2015; Accepted 5 October 2016

Academic Editor: Theodoros C. Rousakis

Copyright (C) 2016 V. P. Berardi. This is an open access article distributed under the Creative Commons Attribution License, which permits unrestricted use, distribution, and reproduction in any medium, provided the original work is properly cited.

A micromechanical procedure is used in order to evaluate the initiation of damage and failure of masonry with in-plane loads. Masonry material is viewed as a composite with periodic microstructure and, therefore, a unit cell with suitable boundary conditions is assumed as a representative volume element of the masonry. The finite element method is used to determine the average stress on the unit cell corresponding to a given average strain prescribed on the unit cell. Finally, critical curves representing the initiation of damage and failure in both clay brick masonry and adobe masonry are provided.

\section{Introduction}

Materials used in civil engineering such as cement concrete [1-4] and masonry are subject to deterioration; moreover, constructions built in the past need to carry increasing seismic horizontal as well as vertical loads, leading to the need for strengthening interventions. Fibre reinforced plastics (FRP), polymeric nets embedded in the plaster, and other more classical materials and techniques are effectively used to strengthen existing structures [5-8]. More complex techniques require the insertion of seismic isolation bearings made of rubber, usually modelled as a hyperelastic material [9-16]. New materials are being tested for civil engineering applications; recently, carbon nanotubes (CNTs) are being used in various research works in order to improve the mechanical properties of cement mortar (usable also in strengthening existing structures); therefore many authors are investigating the behaviour of structures at nanoscale with nonlocal material models [17-21].

Numerical methods for determining the structural response of unreinforced and reinforced masonry constructions, such as arches, wall, and dome, are available in the literature [22-27]. It is important to have available methods for estimating not only the structural response but also the material behaviour. To this end, micromechanics and homogenization methods have been applied to the masonry material. In this work, a micromechanical procedure is used in order to evaluate the initiation of damage and failure of masonry panels with in-plane loads following the approach developed in [28-30].

\section{Micromechanical Analysis and Material Model}

The masonry material is composed of two constituents: the brick and the mortar. These constituents have different mechanical properties and the resulting masonry material can be viewed as a composite so that classical techniques based on micromechanics and homogenization are used in order to determine the local and overall response of the masonry material. The overall mechanical properties of the composite are derived from the geometric and mechanical properties of the constituents, the microstructure of the composite, and so forth. Such information is contained in a reference volume element (RVE), which is statistically representative of the masonry under consideration. The following analyses are performed on the representative volume element. Instead of modelling the masonry as a random composite material (see, e.g., [31-36]), it is assumed that the constituents are arranged in a periodic way [37-45] and a unit cell is adopted as the representative volume element. The 


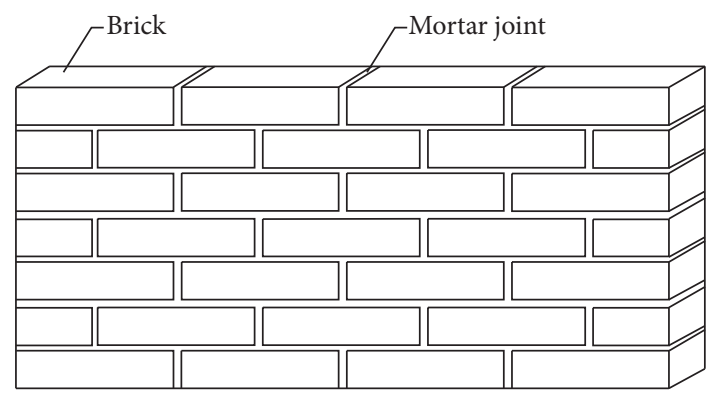

Figure 1: A masonry wall.

masonry considered in this work is shown in Figure 1, where a wall is depicted. The aim is to determine the strength of the masonry when it is subjected to in-plane loads.

The wall in Figure 1 is a three-dimensional structure whose three-dimensional unit cell is shown in Figure 2(a), where $2 a_{1}, 2 a_{2}$, and $2 a_{3}$ are the dimensions of the unit cell along the $x_{1^{-}}, x_{2^{-}}$, and $x_{3}$-axes of the coordinate system with origin in the centre of the unit cell.

In micromechanical and homogenization analyses of periodic microstructure, the three-dimensional unit cell is subjected to the following periodic boundary conditions:

$$
\begin{array}{r}
u_{i}\left(a_{1}, x_{2}, x_{3}\right)-u_{i}\left(-a_{1}, x_{2}, x_{3}\right)=2 E_{i 1} a_{1} \\
\forall x_{2} \in\left[-a_{2}, a_{2}\right], \forall x_{3} \in\left[-a_{3}, a_{3}\right], \\
u_{i}\left(x_{1}, a_{2}, x_{3}\right)-u_{i}\left(x_{1},-a_{2}, x_{3}\right)=2 E_{i 2} a_{2} \\
\forall x_{1} \in\left[-a_{1}, a_{1}\right], \forall x_{3} \in\left[-a_{3}, a_{3}\right], \\
u_{i}\left(x_{1}, x_{2}, a_{3}\right)-u_{i}\left(x_{1}, x_{2},-a_{3}\right)=2 E_{i 3} a_{3} \\
\forall x_{1} \in\left[-a_{1}, a_{1}\right], \forall x_{2} \in\left[-a_{2}, a_{2}\right],
\end{array}
$$

where $u_{i}$ is the displacement along the $x_{i}$-axis and $E_{i j}$ are the components of the average strain prescribed to the unit cell. Together with (1), the following constraint must be imposed in order to avoid the rigid-body translations:

$$
\mathbf{u}\left(\mathbf{x}^{*}\right)=\mathbf{0},
$$

where $\mathbf{x}^{*}$ is the position vector of the centre of the unit cell. Since the in-plane behaviour must be investigated, the plane unit cell shown in Figure 2(b) can be used as representative volume element for a two-dimensional (2D) analysis. In the homogenization analysis, the boundary conditions prescribed to the plane unit cell are

$$
\begin{array}{ll}
u_{i}\left(a_{1}, x_{2}\right)-u_{i}\left(-a_{1}, x_{2}\right)=2 E_{i 1} a_{1} & \forall x_{2} \in\left[-a_{2}, a_{2}\right], \\
u_{i}\left(x_{1}, a_{2}\right)-u_{i}\left(x_{1},-a_{2}\right)=2 E_{i 2} a_{2} & \forall x_{1} \in\left[-a_{1}, a_{1}\right] .
\end{array}
$$

The average stress in the unit cell is denoted by $\boldsymbol{\Sigma}$, whereas the local stress in a point of the constituent of the unit cell is the microstress $\boldsymbol{\sigma}$ and, for simplicity, will be called stress in the following. The constituents (brick and mortar) are considered linear elastic before their damage and failure. The bond between the constituents is considered perfect. It is assumed that the plane unit cell and the constituents are subject to a plane stress state. Therefore, the principal stress perpendicular to the plane unit cell is equal to zero whereas the principal stresses parallel to the plane of the unit cell can be different from zero. The failure in a point of a constituent occurs when one of the following three failure criteria is satisfied.

First Criterion. If the two principal stresses parallel to the plane of the unit cell are nonnegative the failure occurs when the maximum principal stress in a point is equal to the tensile strength of the constituent.

Second Criterion. If the two principal stresses parallel to the plane of the unit cell are nonpositive the failure occurs when the following equation is satisfied:

$$
C J_{2}+(1-C) I_{1}+C I_{2}=1,
$$

where $C=1.6$,

$$
\begin{aligned}
& J_{2}=\frac{1}{f_{c}^{2}}\left(\sigma_{2}-\sigma_{3}\right)^{2}, \\
& I_{1}=\frac{1}{f_{c}}\left(\sigma_{2}+\sigma_{3}\right), \\
& I_{2}=\frac{\sigma_{2} \sigma_{3}}{f_{c}^{2}},
\end{aligned}
$$

where $\sigma_{2}$ and $\sigma_{3}$ are the two nonpositive principal stresses parallel to the plane of the unit cell and $f_{c}$ is the compressive strength of the material of the constituent.

Third Criterion. When a principal stress $\sigma_{1}$ parallel to the plane of the unit cell is nonnegative and the other principal stress $\sigma_{3}$ parallel to the plane of the unit cell is nonpositive, the failure occurs when the following equation is satisfied:

$$
\frac{\sigma_{1}}{f_{t}}+\frac{\sigma_{3}}{f_{c}}=1,
$$

where $f_{t}$ is the tensile strength of the material of the constituent.

Next, the average strain $\mathbf{E}$ (which is a tensor with components $E_{i j}$ ) is imposed on the plane unit cell by means of the conditions (2) and (3). Then, the average stress $\boldsymbol{\Sigma}$ corresponding to the prescribed average strain $\mathbf{E}$ is evaluated and the critical curves of the masonry are determined with a finite element homogenization technique. The critical curves may be plotted in the plane defined by $\Sigma_{11^{-}}$and $\Sigma_{22}$-axes or in the plane defined by $\Sigma_{11^{-}}$and $\Sigma_{12}$-axes. There are two kinds of critical curves: a generic critical curve may be related to the brick or to the mortar. The generic point of the critical curve related to a constituent represents the average stresses corresponding to the initiation of failure of that constituent. Specifically, the initiation of failure of a constituent is evaluated by prescribing a linear load path $\mathbf{E}=\lambda \mathbf{E}^{0}$, where $\mathbf{E}^{0}$ is a constant tensor, which does not vary in the loading process, and the scalar $\lambda$ is an increasing loading positive parameter. Considering both constituents linear 


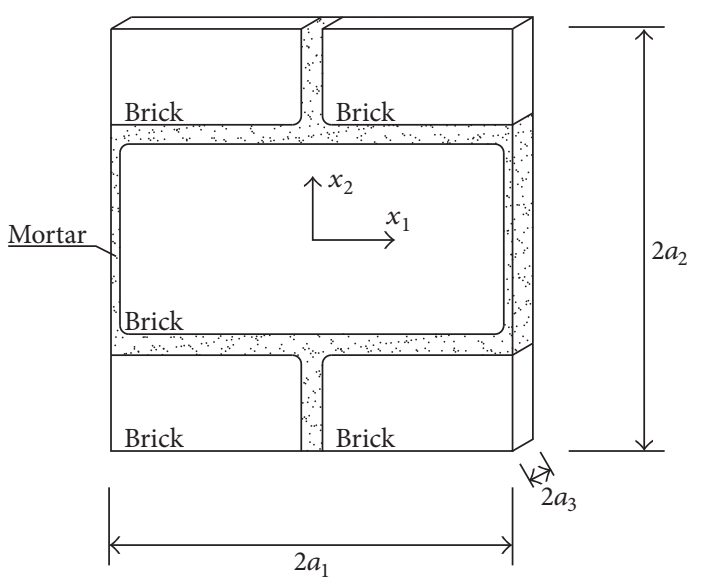

(a)

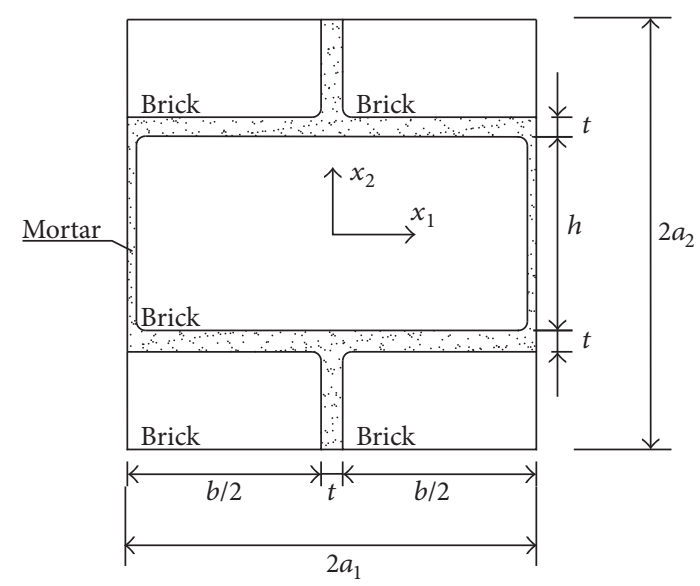

(b)

Figure 2: (a) Three-dimensional unit cell; (b) plane unit cell.

elastic, there exists a value $\lambda^{\mathrm{cr}, i}$ such that the microstresses in a constituent $i$ ( $i=$ brick or mortar) of the unit cell subject to the average strain $\mathbf{E}=\lambda^{\mathrm{cr}, i} \mathbf{E}^{0}$ satisfy some of the abovementioned criteria in the same constituent $i$, whereas failure criteria are not satisfied in the same constituent $i$ when the unit cell is subject to $\mathbf{E}=\lambda \mathbf{E}^{0}$ for $0 \leq \lambda<\lambda^{\mathrm{cr}, i}$. The average stress of the unit cell subject to the average strain $\mathbf{E}=\lambda^{\mathrm{cr}, i} \mathbf{E}^{0}$ is denoted by $\Sigma^{\text {cr, } i}$. In the plane defined by $\Sigma_{11}$-and $\Sigma_{22}$-axes, the components $\left(\Sigma_{11}^{\mathrm{cr}, i}, \Sigma_{22}^{\mathrm{cr}, i}\right)$ of $\boldsymbol{\Sigma}^{\mathrm{cr}, i}$ define a closed curve which represents the masonry critical curve related to the initiation of failure of the constituent $i$. An analogous critical curve can be plotted in the plane defined by $\Sigma_{11}$ - and $\Sigma_{12}$-axes.

\section{Numerical Examples}

If the constituents have the same mechanical properties and the bond between the brick and the mortar is perfect, the masonry behaves like a homogeneous material and the homogenization procedure is not required. Critical cases occur when the mechanical properties of one constituent are significantly different from the mechanical properties of the other constituents. For example, in adobe masonry (AM), bricks and mortar have similar elastic properties, whereas in some kinds of clay brick masonry (CBM) Young's modulus of the brick may be significantly different from Young's modulus of the mortar. The masonry critical curves are very sensitive to the ratio $E_{b} / E_{m}$, where $E_{b}$ and $E_{m}$ are Young's moduli of the brick and the mortar, respectively. This is shown in Figure 3, where the masonry critical curve related to the initiation of failure of the constituent $i$ is denoted by " $b$ " for $i=$ brick and by " $m$ " for $i=$ mortar in the legend of the figure.

The critical curves in Figure 3 are obtained by prescribing the following average strain:

$$
\mathbf{E}=\left[\begin{array}{ll}
E_{11} & E_{12} \\
E_{21} & E_{22}
\end{array}\right]=\lambda\left[\begin{array}{cc}
\cos \varphi & 0 \\
0 & \sin \varphi
\end{array}\right] \quad \text { for } \varphi \in[0,2 \pi]
$$

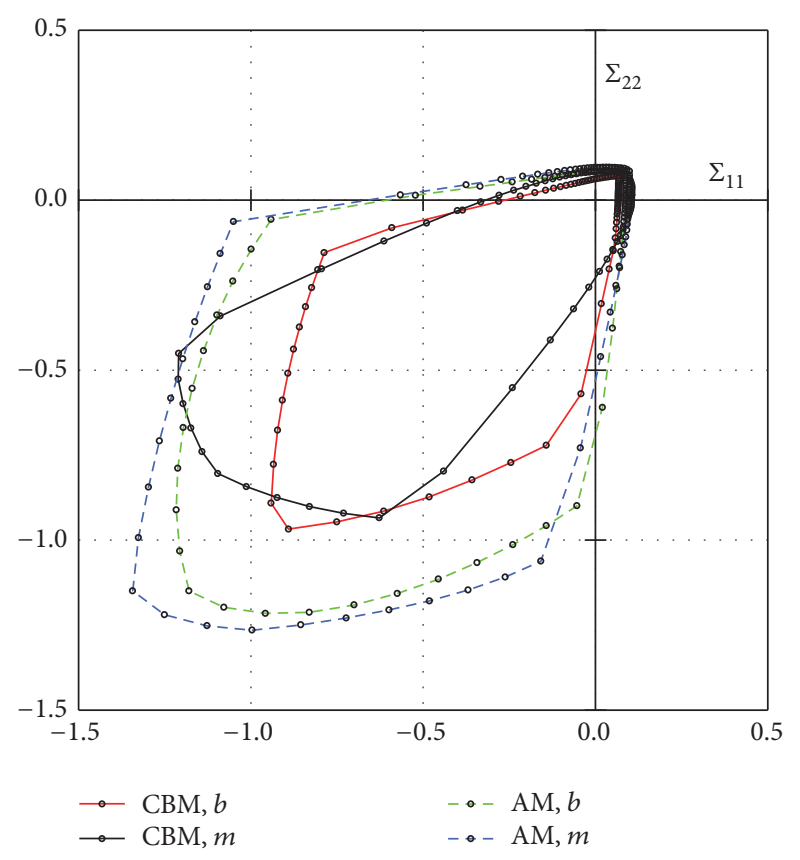

FIGURE 3: CBM and AM critical curves, in the $\Sigma_{11}-\Sigma_{22}$ plane, related to the initiation of failure of brick and mortar.

In this section, the mechanical properties of the constituents of CBM are $v_{b}=0.23, v_{m}=0.15, E_{b}=10 E_{m}=$ $10000 \mathrm{MPa}, f_{c b}=10 f_{t b}=1 \mathrm{MPa}, f_{c m}=f_{c b}$, and $f_{t m}=f_{t b}$; the mechanical properties of the constituents of AM are $v_{b}$ $=v_{m}=0.15, E_{b}=2 E_{m}=100 \mathrm{MPa}, f_{c b}=10 f_{t b}=1 \mathrm{MPa}, f_{c m}$ $=f_{c b}$, and $f_{t m}=f_{t b}$. In this work, $v_{b}$ and $v_{m}$ are Poisson's ratios of the brick and the mortar, respectively, $f_{t b}$ and $f_{t m}$ are the tensile strengths of the brick and the mortar, and $f_{c b}$ and $f_{c m}$ are the compressive strengths of the brick and the mortar. Both CBM and AM have the following geometric properties: $b=400 \mathrm{~mm}$ (width of the bricks), $h=100 \mathrm{~mm}$ (height of the bricks), $t=10 \mathrm{~mm}$ (thickness of mortar joints), and 


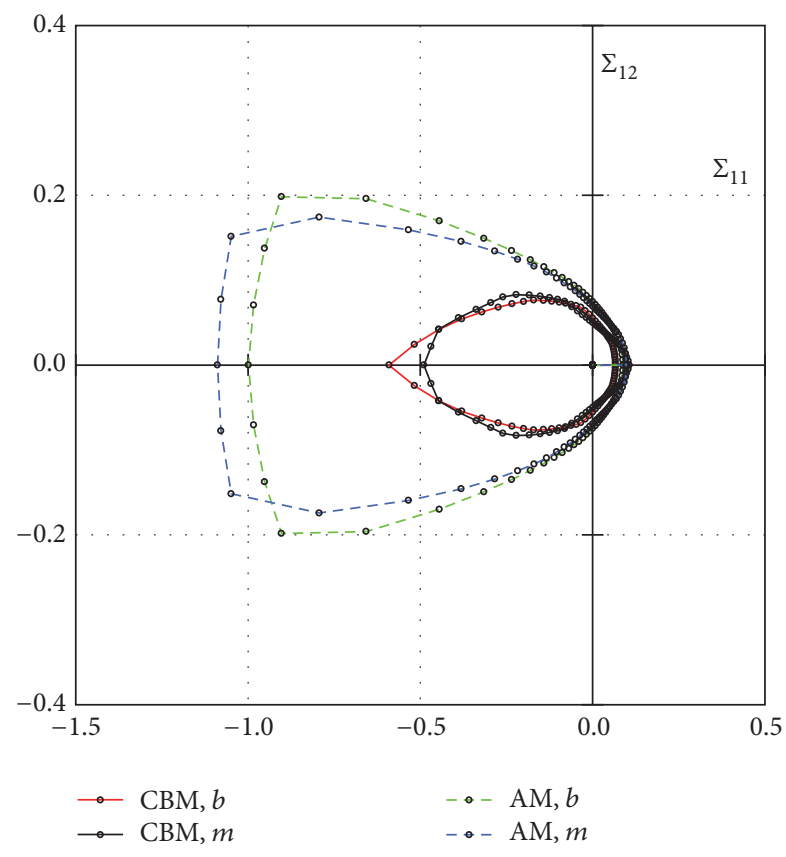

FIGURE 4: CBM and AM critical curves, in the $\Sigma_{11}-\Sigma_{12}$ plane, related to the initiation of failure of brick and mortar.

$\rho=h / 40$ (each brick corner was approximated as arc of circle with radius $\rho$ ).

In Figure 3, two different values of the ratio $c=E_{b} / E_{m}$ are considered: $c=10$ for the CBM critical curves and $c=2$ for the AM critical curves. Greater values of $c$ determine greater concentration of the local stress and, as a consequence, smaller critical areas (the critical area is the area bounded by the critical curve related to the initiation of failure of a constituent). A similar behaviour is observed in Figure 4, where the critical curves are obtained by prescribing the following average strain:

$$
\mathbf{E}=\left[\begin{array}{ll}
E_{11} & E_{12} \\
E_{21} & E_{22}
\end{array}\right]=\lambda\left[\begin{array}{cc}
\cos \varphi & \sin \varphi \\
\sin \varphi & 0
\end{array}\right] \quad \text { for } \varphi \in[0,2 \pi]
$$

The contrast $c$ between the masonry constituents also influences the deformed shape of the unit cell and the distribution of local stress in the unit cell, as shown in Figures 5 and 6 , where the local stress $\sigma_{12}$ on the deformed unit cell subject to the average strain (8) with $\varphi=\pi / 2$ and $\lambda=1$ is plotted for CBM $(c=10)$ and $\mathrm{AM}(c=2)$, respectively.

\section{Conclusions}

In this work, masonry is viewed as a composite constituted of two components (namely, brick and mortar) so that classical techniques based on micromechanics and homogenization are used in order to determine the local and overall response of the masonry material. The critical curves of the masonry are determined with a finite element homogenization technique. The generic point of the critical curve related to a constituent represents the average stresses corresponding to the initiation of failure of that constituent. The numerical

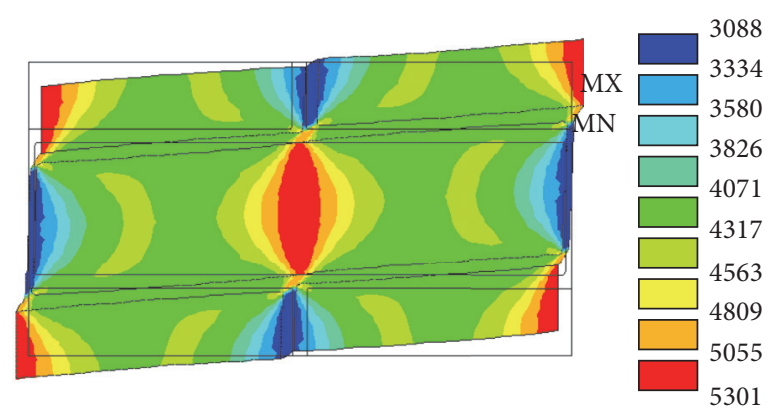

FIgURE 5: Local stress $\sigma_{12}$ on the deformed CBM unit cell subject to a pure shear average strain $E_{12}=E_{21}=1$.

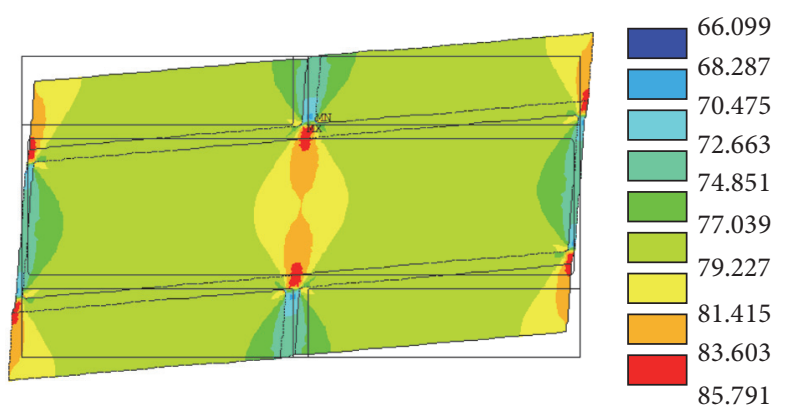

FIGURE 6: Local stress $\sigma_{12}$ on the deformed AM unit cell subject to a pure shear average strain $E_{12}=E_{21}=1$.

analyses show that the critical curves are sensitive to the contrast $c=E_{b} / E_{m}$ between brick and mortar: greater contrast involves earlier initiation of damage in the constituents.

\section{Competing Interests}

There are no competing interests related to this paper.

\section{References}

[1] A. Caporale, L. Feo, and R. Luciano, "Damage mechanics of cement concrete modeled as a four-phase composite," Composites Part B: Engineering, vol. 65, pp. 124-130, 2014.

[2] A. Caporale and R. Luciano, "A micromechanical four-phase model to predict the compressive failure surface of cement concrete," Frattura ed Integrita Strutturale, vol. 8, no. 29, pp. 1927, 2014.

[3] G. Dinelli, G. Belz, C. E. Majorana, and B. A. Schrefler, "Experimental investigation on the use of fly ash for lightweight precast structural elements," Materials and Structures, vol. 29, no. 10, pp. 632-638, 1996.

[4] G. Xotta, G. Mazzucco, V. A. Salomoni, C. E. Majorana, and K. J. Willam, "Composite behavior of concrete materials under high temperatures," International Journal of Solids and Structures, vol. 64, pp. 86-99, 2015.

[5] A. D’Ambrisi, F. Focacci, and R. Luciano, "Experimental investigation on flexural behavior of timber beams repaired with CFRP plates," Composite Structures, vol. 108, no. 1, pp. 720-728, 2014.

[6] A. D’Ambrisi, F. Focacci, R. Luciano, V. Alecci, and M. De Stefano, "Carbon-FRCM materials for structural upgrade of 
masonry arch road bridges," Composites Part B: Engineering, vol. 75, no. 3373, pp. 355-366, 2015.

[7] A. D’Ambrisi, M. Mezzi, and A. Caporale, "Experimental investigation on polymeric net-RCM reinforced masonry panels," Composite Structures, vol. 105, pp. 207-215, 2013.

[8] V. Salomoni, G. Mazzucco, C. Pellegrino, and C. Majorana, "Three-dimensional modelling of bond behaviour between concrete and FRP reinforcement," Engineering Computations, vol. 28, no. 1, pp. 5-29, 2011.

[9] A. M. Tarantino, "The singular equilibrium field at the notch-tip of a compressible material in finite elastostatics," Zeitschrift für Angewandte Mathematik und Physik, vol. 48, no. 3, pp. 370-388, 1997.

[10] A. M. Tarantino, "On extreme thinning at the notch tip of a neoHookean sheet," The Quarterly Journal of Mechanics and Applied Mathematics, vol. 51, no. 2, pp. 179-190, 1998.

[11] A. M. Tarantino, "On the finite motions generated by a mode I propagating crack," Journal of Elasticity. The Physical and Mathematical Science of Solids, vol. 57, no. 2, pp. 85-103 (2000), 1999.

[12] A. M. Tarantino, "Asymmetric equilibrium configurations of symmetrically loaded isotropic square membranes," Journal of Elasticity, vol. 69, no. 1-3, pp. 73-97, 2002.

[13] A. M. Tarantino, "Asymmetric equilibrium configurations of hyperelastic cylindrical bodies under symmetric dead loads," Quarterly of Applied Mathematics, vol. 64, no. 4, pp. 605-615, 2006.

[14] A. M. Tarantino and A. Nobili, "Constitutive branching analysis of cylindrical bodies under in-plane equibiaxial dead-load tractions," International Journal of Non-Linear Mechanics, vol. 41, no. 8, pp. 958-968, 2006.

[15] A. M. Tarantino, "Homogeneous equilibrium configurations of a hyperelastic compressible cube under equitriaxial dead-load tractions," Journal of Elasticity. The Physical and Mathematical Science of Solids, vol. 92, no. 3, pp. 227-254, 2008.

[16] L. Lanzoni and A. M. Tarantino, "Damaged hyperelastic membranes," International Journal of Non-Linear Mechanics, vol. 60, pp. 9-22, 2014.

[17] A. Apuzzo, R. Barretta, and R. Luciano, "Some analytical solutions of functionally graded Kirchhoff plates," Composites Part B: Engineering, vol. 68, pp. 266-269, 2015.

[18] R. Barretta, L. Feo, and R. Luciano, "Torsion of functionally graded nonlocal viscoelastic circular nanobeams," Composites Part B: Engineering, vol. 72, pp. 217-222, 2015.

[19] R. Barretta, L. Feo, R. Luciano, and F. Marotti de Sciarra, "A gradient Eringen model for functionally graded nanorods," Composite Structures, vol. 131, pp. 1124-1131, 2015.

[20] R. Barretta, L. Feo, R. Luciano, and F. Marotti de Sciarra, "Variational formulations for functionally graded nonlocal BernoulliEuler nanobeams," Composite Structures, vol. 129, pp. 80-89, 2015.

[21] R. Barretta, R. Luciano, and F. Marotti De Sciarra, "A fully gradient model for Euler-Bernoulli nanobeams," Mathematical Problems in Engineering, vol. 2015, Article ID 495095, 8 pages, 2015.

[22] A. Caporale, R. Luciano, and L. Rosati, "Limit analysis of masonry arches with externally bonded FRP reinforcements," Computer Methods in Applied Mechanics and Engineering, vol. 196, no. 1-3, pp. 247-260, 2006.
[23] A. Caporale, L. Feo, and R. Luciano, "Limit analysis of FRP strengthened masonry arches via nonlinear and linear programming," Composites Part B: Engineering, vol. 43, no. 2, pp. 439-446, 2012.

[24] A. Caporale and R. Luciano, "Limit analysis of masonry arches with finite compressive strength and externally bonded reinforcement," Composites Part B: Engineering, vol. 43, no. 8, pp. 3131-3145, 2012.

[25] A. Caporale, L. Feo, R. Luciano, and R. Penna, "Numerical collapse load of multi-span masonry arch structures with FRP reinforcement," Composites Part B: Engineering, vol. 54, no. 1, pp. 71-84, 2013.

[26] A. D’Ambrisi, F. Focacci, and A. Caporale, "Strengthening of masonry-unreinforced concrete railway bridges with PBOFRCM materials," Composite Structures, vol. 102, pp. 193-204, 2013.

[27] A. Caporale, L. Feo, D. Hui, and R. Luciano, "Debonding of FRP in multi-span masonry arch structures via limit analysis," Composite Structures, vol. 108, no. 1, pp. 856-865, 2014.

[28] A. Caporale, F. Parisi, D. Asprone, R. Luciano, and A. Prota, "Critical surfaces for adobe masonry: micromechanical approach," Composites Part B: Engineering, vol. 56, pp. 790796, 2014.

[29] A. Caporale, F. Parisi, D. Asprone, R. Luciano, and A. Prota, "Micromechanical analysis of adobe masonry as twocomponent composite: influence of bond and loading schemes," Composite Structures, vol. 112, no. 1, pp. 254-263, 2014.

[30] A. Caporale, F. Parisi, D. Asprone, R. Luciano, and A. Prota, "Comparative micromechanical assessment of adobe and clay brick masonry assemblages based on experimental data sets," Composite Structures, vol. 120, pp. 208-220, 2015.

[31] R. Luciano and J. R. Willis, "Bounds on non-local effective relations for random composites loaded by configurationdependent body force," Journal of the Mechanics and Physics of Solids, vol. 48, no. 9, pp. 1827-1849, 2000.

[32] R. Luciano and J. R. Willis, "Non-local effective relations for fibre-reinforced composites loaded by configurationdependent body forces," Journal of the Mechanics and Physics of Solids, vol. 49, no. 11, pp. 2705-2717, 2001.

[33] R. Luciano and J. R. Willis, "Non-local constitutive response of a random laminate subjected to configuration-dependent body force," Journal of the Mechanics and Physics of Solids, vol. 49, no. 2, pp. 431-444, 2001.

[34] R. Luciano and J. R. Willis, "Boundary-layer corrections for stress and strain fields in randomly heterogeneous materials," Journal of the Mechanics and Physics of Solids, vol. 51, no. 6, pp. 1075-1088, 2003.

[35] R. Luciano and J. R. Willis, "FE analysis of stress and strain fields in finite random composite bodies," Journal of the Mechanics and Physics of Solids, vol. 53, no. 7, pp. 1505-1522, 2005.

[36] R. Luciano and J. R. Willis, "Hashin-Shtrikman based FE analysis of the elastic behaviour of finite random composite bodies," International Journal of Fracture, vol. 137, no. 1-4, pp. 261-273, 2006.

[37] A. Caporale, R. Luciano, and E. Sacco, "Micromechanical analysis of interfacial debonding in unidirectional fiber-reinforced composites," Computers and Structures, vol. 84, no. 31-32, pp. 2200-2211, 2006.

[38] A. Caporale and R. Luciano, "Micromechanical analysis of periodic composites by prescribing the average stress," Annals of Solid and Structural Mechanics, vol. 1, no. 3, pp. 117-137, 2010. 
[39] A. Caporale, R. Luciano, and R. Penna, "Fourier series expansion in non-orthogonal coordinate system for the homogenization of linear viscoelastic periodic composites," Composites Part B: Engineering, vol. 54, no. 1, pp. 241-245, 2013.

[40] A. Caporale, L. Feo, and R. Luciano, "Eigenstrain and Fourier series for evaluation of elastic local fields and effective properties of periodic composites," Composites Part B: Engineering, vol. 81, pp. 251-258, 2015.

[41] F. Greco and R. Luciano, "A theoretical and numerical stability analysis for composite micro-structures by using homogenization theory," Composites Part B: Engineering, vol. 42, no. 3, pp. 382-401, 2011.

[42] G. Cricrì and R. Luciano, "Homogenised properties of composite materials in large deformations," Composite Structures, vol. 103, pp. 9-17, 2013.

[43] D. Bruno, F. Greco, R. Luciano, and P. Nevone Blasi, "Nonlinear homogenized properties of defected composite materials," Computers and Structures, vol. 134, pp. 102-111, 2014.

[44] L. Feo, F. Greco, L. Leonetti, and R. Luciano, "Mixed-mode fracture in lightweight aggregate concrete by using a moving mesh approach within a multiscale framework," Composite Structures, vol. 123, pp. 88-97, 2015.

[45] F. Greco, L. Leonetti, and R. Luciano, "A multiscale model for the numerical simulation of the anchor bolt pull-out test in lightweight aggregate concrete," Construction and Building Materials, vol. 95, no. 6986, pp. 860-874, 2015. 


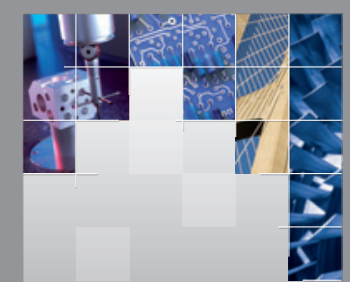

\section{Enfincering}
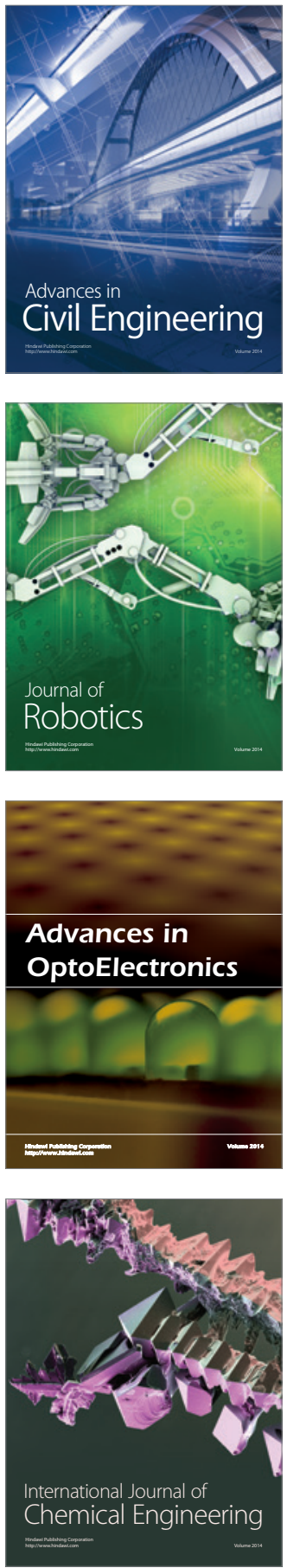

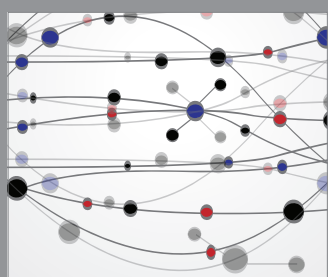

The Scientific World Journal

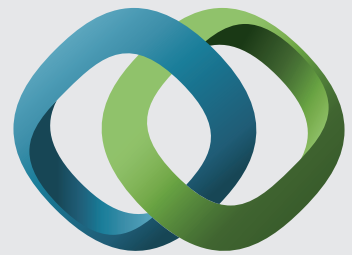

\section{Hindawi}

Submit your manuscripts at

http://www.hindawi.com
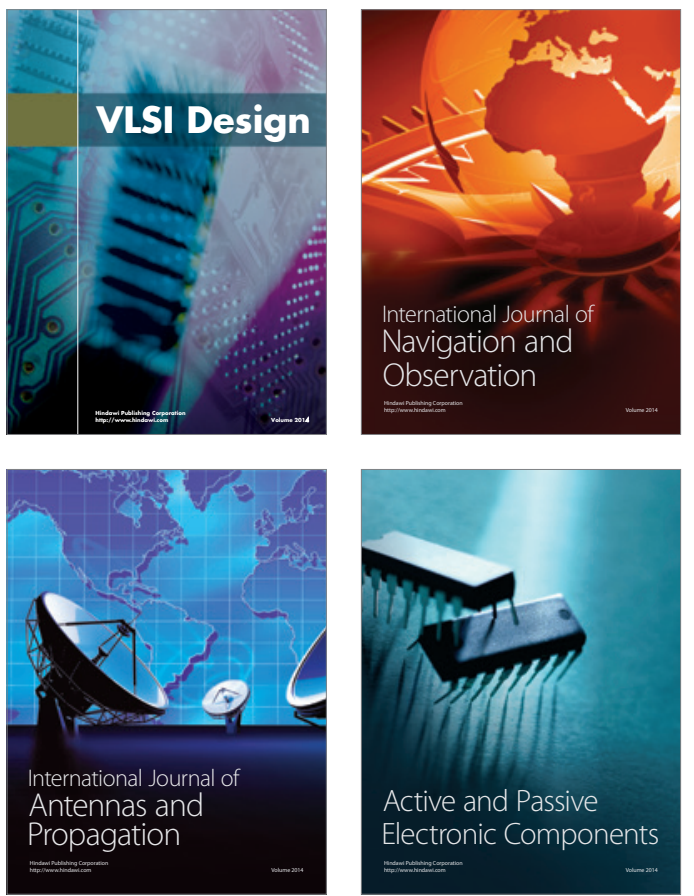
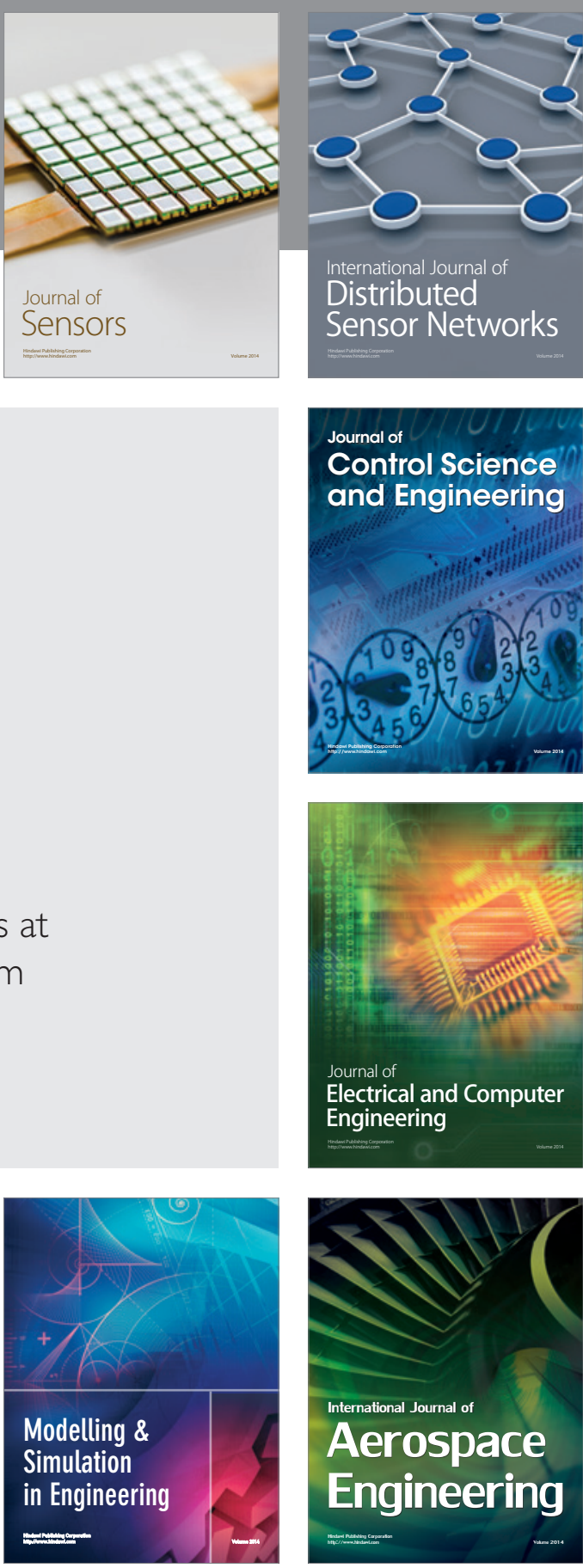

International Journal of

Distributed

Sensor Networks

Journal of

Control Science

and Engineering
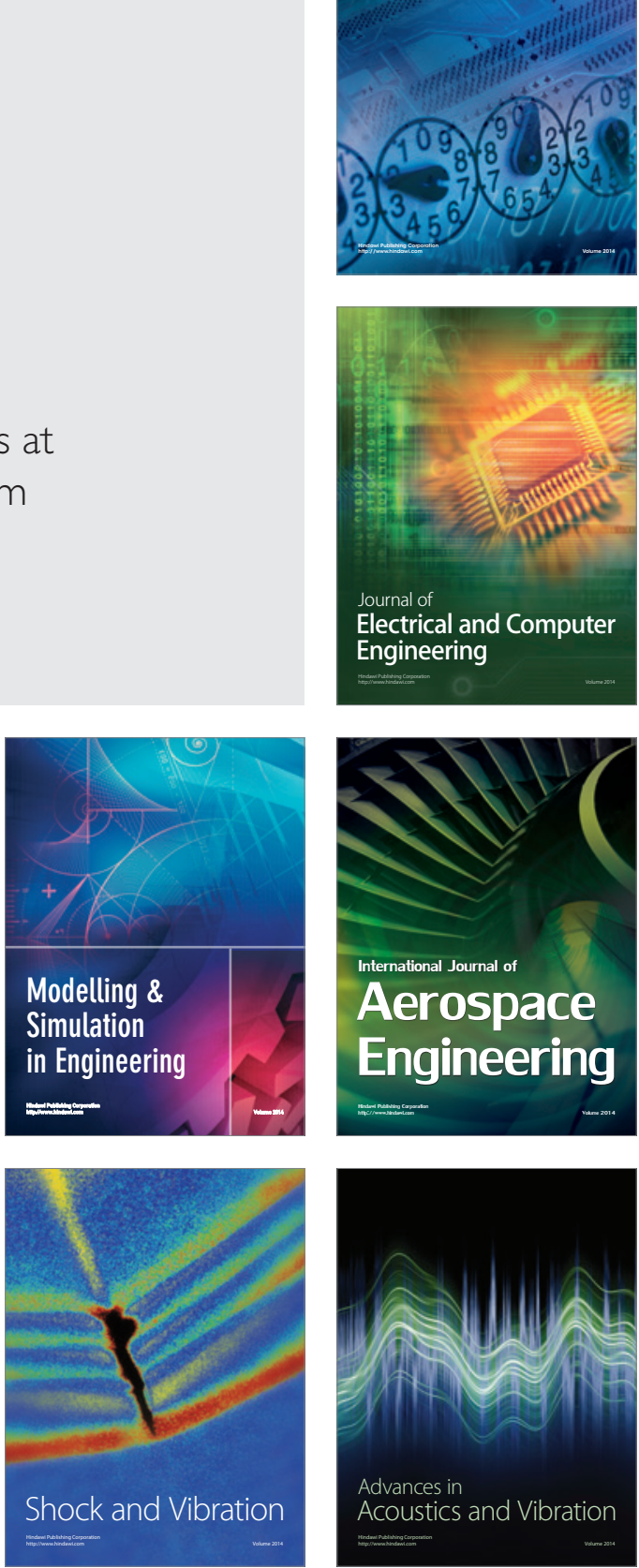